\title{
Técnicas de investigación en deporte
}

XAVIER BALIUS

Centre d'Alt Rendiment (CAR). Sant Cugat del Vallés

La investigación biomecánica ha estado desde finales de la década de los 60 y durante la década de los 70 , íntimamente relacionada con la cinematografía, que podemos considerar una de las principales impulsoras de la biomecánica que hoy en día conocemos.

Evidentemente la investigación biomecánica hace ya décadas que esta en práctica, como lo demuestran los estudios de autores como Braune \& Fisher (1889), Dempster (1955), y Havanan (1964), sobre determinación de masas corporales, centro de masas, densidades, y momentos de inercia. En cuanto a la cinematografía y biomecánica, existen también estudios realizados ya en el siglo pasado en base a la sucesión de fotografías, como los estudios realizados por Marey hacia 1880 .

La cinematografía como herramienta de la investigación biomecánica es un sistema de medición indirecta cuya utilidad es la de explicar y describir el rendimiento deportivo, teniendo en cuenta al deportista y la técnica a investigar, el equipamiento que utiliza para la práctica de su deporte, y el medio en el que se desenvuelve. Como resultado de esta explicación y esta descripción, el biomecánico ayudará a la mejora del rendimiento del deportista, y la mejora de la calidad de vida del individuo en general.

De hecho, si habláramos simplemente de cinematografía, la medición realizada podría ser considerada como directa puesto que los resultados provenientes de la imagen nos proporcionan una respuesta (feedback) real de lo acontecido. Pero la cinematografía en sí es solo un instrumento, un primer paso hacia un resultado imperceptible para el ojo humano.

Las cámaras cinematográficas capaces de registrar más de 1000 imágenes por segundo (Locamm, Fotosonic) proporcionan una cantidad de información cuyo almacenaje y tratamiento solo puede ser entendido bajo la óptica del ordenador, otro monstruo de los años 70 que ha agilizado la invetigación en deporte en una simbiosis casi perfecta con la cinematografía.

El proyector cinematográfico será el encargado de detener cada vez una imagen que sera proyectada sobre la pantalla digitalizadora. El proyector, cuyo eje óptico será perpendicular a dicha pantalla, deberá enfocar perfectamente la imagen y permanecerá estático durante todo el proceso de digitalización del gesto deportivo.

Mediante un cursor (ratón) que es desplazado manualmente sobre la pantalla digitalizadora, y por tanto sobre la imgen, se digitalizan los datos de interés para el análi- sis biomecánico. El cursor es capaz de introducir al ordenador la posición de cualquier articulación del cuerpo cinematografiado representada con un punto dentro de un sistema de coordenadas. De esta manera se irán introduciendo al ordenador los puntos corporales específicos para nuestro estudio, por cada imagen, y por tantas imágenes como especifiquemos.

En el ordenador y almacenado en un fichero del mismo, solo existirán un sin fin de números. Con la ayuda de sofisticados programas podrán realizarse los cálculos matemáticos para la obtención de parámetros para la interpretación de imágenes (DLT), el filtrado de los resultados y la obtención de datos biomecánicos para el análisis del gesto deportivo (Knowned, Indiana).

Estos datos cinemáticos referentes a la posición de un cuerpo en el espacio, su desplazamiento, velocidad, aceleración, distribución de masas; y cinéticos como las características inerciales del cuerpo, fuerzas internas y/o externas y sus líneas de acción, podrán ser estadísticamente tratados. Posteriormente estos resultados serán comunicados al entrenador el cual deberá adoptar las medidas apropiadas para resolver problemas en base a la información biomecánica transmitida.

En relación al análisis biomecánico a partir de la cinematografía hay que matizar dos puntos: el calibraje y la precisión. Mucha gente se preguntará si es tan sencillo el análisis biomecánico como el hecho de filmar una acción deportiva. Antes de filmar cualquier acción, o al finalizarla, deberemos filmar lo que llamamos objeto control. El objeto control es el instrumento indispensable para la calibración del espacio donde se realiza el gesto deportivo. Si antes hablábamos de un punto en un centro de coordenadas, sino que es precisamente el resultado de la filmación y posterior digitalización de una serie de puntos cuya distancia entre ellos es conocida. Estos valores serán los que después del primer cálculo matemático, den a un punto del cuerpo en el espacio un sentido posicional. Si el estudio es realizado con una cámara, dicho estudio será el análisis bidimensional del gesto en cuestión. Por otro lado si el estudio se realiza con dos o más cámaras que filman el mismo gesto al mismo tiempo, desde posiciones distintas, el estudio será tridimensional.

Cada una de estas cámaras proporcionará datos bidimensionales de la acción desde distintas perspectivas. Estos datos sufrirán entonces un proceso de cálculo matemático, el ya nombrado DLT, cuyo resultado se traducirá en una representación gráfica tridimensional de la acción deportiva. Las ventajas de esta representación 
gráfica son claras, la figura representada podrá ser manipulada y observada desde cualquier perspectiva espacial deseada, facilitándose así el análisis de algunos de los gestos deportivos más complejos. Hay que aclarar que el incremento en número de cámaras disminuye el error global del análisis, debido a un incremento de la información inicial adquirida. Esta disminución del error viene condicionada también por la capacidad digitalizadora que ofrece la cinematografía, actualmente superior a las nuevas técnicas de videografía.

Como todo instrumento de medición, la cinematografía tiene sus ventajas y sus inconvenientes. Se ha dicho que el instrumento ideal debe ser simple, rápido, remoto (es decir, que no perjudique la acción deportiva), de bajo coste económico, y válido para investigar realmente lo que se desea investigar.

En relación a los inconvenientes la cinematografía no es una técnica de medición simple, puesto que su preparación la hace incómoda para un mundo como el deporte que no puede esperar a que se cambie la película una cámara. Es una técnica lenta, puesto que la necesidad de revelado del film retrasa la obtención de resultados. Y es una técnica de alto coste económico debido a la complejidad de las cámaras y proyectores, además de la adquisición de películas y su posterior revelado.
En relación a las ventajas, la cinematografía es una técnica remota, y su precisión es mayor que las nuevas tecnologías, siendo su validez indiscutible; pero ello no significa que estas nuevas tecnologías no tengan, de todas maneras una alta precisión.

En 1880 Marey lograba mediante la colocación de placas metálicas sobre las extremidades del individuo, y gracias a la sucesión de flashes durante una única exposición, un efecto muy parecido a los modelos actuales informatizados. Las diferencias claro está, son el enorme volumen de información que hoy día poseemos, y unos 100 años de evolución. Evolución que se ha derivado hacia las más futuristas visualizaciones llevada a cabo en el CAR de Sant Cugat, en Barcelona.

\section{REFERENCIAS}

- Winter, David A. «Biomechanics of Human Movement» John Wiley \& Sons, Inc. 1979.

- Rouillé, André \& Marbot, Bernard «Le corps et son image» Contrejour 1986.

- Atha, J. "Currente Techniques for Measuring Motion» Applied Ergonomics 15.4, 245-257, 1984. 